Int. J. Dev. Biol. 58: 693-699 (2014)

doi: $10.1387 / \mathrm{ijdb} .140288 \mathrm{jp}$

\title{
Construction and characterization of a sox9b transgenic reporter line
}

\author{
JESSICA S. PLAVICKI*,1,3, TRACIE. R. BAKER ${ }^{1,3}$, FELIPE R. BURNS ${ }^{1,3}, K^{\prime} O N G$ M. XIONG ${ }^{2}$ ALEX J. GOODING ${ }^{1}$, \\ PETER HOFSTEEN ${ }^{1}$, RICHARD E. PETERSON ${ }^{1,3}$ and WARREN HEIDEMAN ${ }^{1,3}$

\begin{abstract}
${ }^{1}$ School of Pharmacy, ${ }^{2}$ Department of Biomolecular Chemistry and ${ }^{3}$ Molecular and Environmental Toxicology Center, School of Pharmacy, University of Wisconsin-Madison, Madison, WI, USA
\end{abstract}

\begin{abstract}
The transcription factor SOX9 is a member of the SRY-related high-mobility-group box (SOX) superfamily of genes. In mammals, Sox9 plays important roles in many developmental processes including craniofacial, skeletal and heart morphogenesis, retinal and brain development, and gonad differentiation. Human mutations in $S O X 9$ or the SOX9 promoter result in campomelic dysplasia, a severe genetic disorder, which disrupts skeletal, craniofacial, cardiac, neural and reproductive development. Due to the duplication of the teleost fish genome, zebrafish (Danio rerio) have two Sox9 genes: sox9a and sox9b. Loss of sox9b in zebrafish results in loss of function phenotypes that are similar to those observed in humans and mice. In order to generate a transgenic sox9b:EGFP reporter line, we cloned a $2450 \mathrm{bp}$ fragment of the sox $9 \mathrm{~b}$ promoter and fused it to an EGFP reporter. Consistent with reported sox $9 b$ expression and function, we observed sox9b:EGFP in the developing heart, skeletal and craniofacial structures, brain, retina, and ovaries. Our resulting transgenic line is a useful tool for identifying and studying sox $9 b$ function in development and visualizing a number of zebrafish organs and tissues in which sox9b is normally expressed.
\end{abstract}

KEY WORDS: sox9b, Sox9, SOX9, zebrafish, heart, craniofacial, skeletal, ovary, brain, campomelic dysplasia

SOX9 encodes a transcription factor that is a member of the SRYrelated high-mobility-group box (SOX) superfamily of genes. Sox9 plays critical roles in craniofacial and heart morphogenesis (Hofsteen et al., 2013; Smith et al., 2011; Yan et al., 2005; Yokoi et al., 2009), as well as retinal and brain development (Esain et al., 2010; Scott et al., 2010; Stolt et al., 2003; Yan et al., 2005), and gonad differentiation (Morais da Silva et al., 1996). In humans, mutations that reduce SOX9 function produce campomelic dysplasia (CD), a severe genetic disorder (Foster et al., 1994; Wagner et al., 1994).

Individuals with $C D$ have numerous skeletal malformations including femoral and tibial bowing, vertebral hypoplasia, cervical spine malformations, as well as underdeveloped shoulder blades and pelvic bones, and 11 pairs of ribs. CD patients also exhibit the Pierre Robin sequence, which is characterized by congenital facial abnormalities, incomplete closure of the roof of the mouth (cleft palate), small jaw/mandible (micrognathia) and posterior positioning of the tongue because of changes in jaw structure (glossoptosis) (Foster et al., 1994; Wagner et al., 1994). In addition, individuals with CD exhibit Tetratology of Fallot, a set of four concurrent congenital cardiac abnormalities that include ventricular septal defect, overriding aorta, pulmonary stenosis, and right ventricular hypertrophy (Foster et al., 1994; Wagner et al., 1994). Furthermore, CD is associated with autosomal $X Y$ sex reversal (Foster et al., 1994; Wagner et al., 1994), in which genetic males appear, based on primary and secondary sexual characteristics, to develop as females.

Due to the teleost fish genome duplication, zebrafish (Danio rerio) have two Sox9 genes, sox9a and sox9b (Chiang et al., 2001). sox9a and sox9b have both overlapping and distinct expression domains as well as shared and divergent functions (Yan et al., 2005). We focused on constructing a tool for specifically visualizing sox9b expression, because we are interested in understanding the molecular mechanisms that underlie phenotypes resulting from

Abbreviations used in this paper: CD, campomelic dysplasia; EGFP, enhanced green fluorescent protein; hpf, hours post fertilization; sox $9 \mathrm{~b}$, sex determining region on the Y chromosome-box 9b, TCDD, 2,3,7,8-tetrachlorodibenzo-p-dioxin.

\footnotetext{
*Address correspondence to: Dr. Jessica S. Plavicki. 777 Highland Avenue, Madison, WI 53705-2222, USA. Tel: +1-608-262-4525. Fax: +1-608-262-5343.

E-mail: plavicki@wisc.edu
}

Supplementary Material (1 table and 1 figure) for this paper is available at: http://dx.doi.org/10.1387/ijdb.140288jp

Accepted: 7 December 2014.

ISSN: Online 1696-3547, Print 0214-6282

(C) 2014 UBC Press

Printed in Spain 


\begin{tabular}{|l|l|l|l|l|l|l|l|l|}
\hline & 63.181 & 63.182 & 63.183 & 63.184 & 63.185 & 63.186 & 63.187 & 63.188 \\
\hline
\end{tabular}

Fig. 1. Schematic comparing the cloned 2450 sox $9 b$ promoter sequence in builds Zv7 and Zv9. BLAT of the cloned $2450 \mathrm{bp}$ sox9b promoter sequence in build Zv7 with the sequence in build Zv9. Both a short region adjacent to the transcriptional start site and $a \sim 1.1 \mathrm{~kb}$ region align well. However approximately $1.4 \mathrm{~kb}$ has no alignment in build Zv9 and has been replaced by a unique sequence. Solid black bars in the Zv7 promoter sequence schematic indicate areas of sequence alignment. Red regions indicate areas where the sequences in $Z v 7$ and $Z v 9$ do not align.

exposure to the persistent environmental contaminant, 2,3,7,8-tetrachlorodibenzo-p-dioxin (TCDD). Embryonic TCDD exposure produces numerous developmental defects including craniofacial malformations, heart malformations, and impairs regenerative capacity. TCDD exposure also results in the downregulation of sox $9 \mathrm{~b}$ in the developing jaw, heart and the regenerating fin, all tissues in which TCDD-induced phenotypes are observed (reviewed in KingHeiden at al, 2012). Thus, indicating that loss of sox9b expression is likely an important factor mediating the observed phenotypes. Consistent with this hypothesis and similar to the loss of function

A

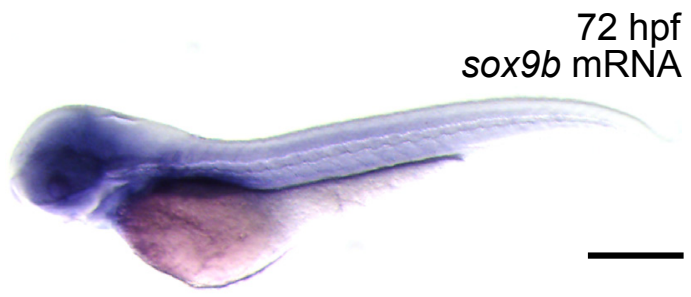

B

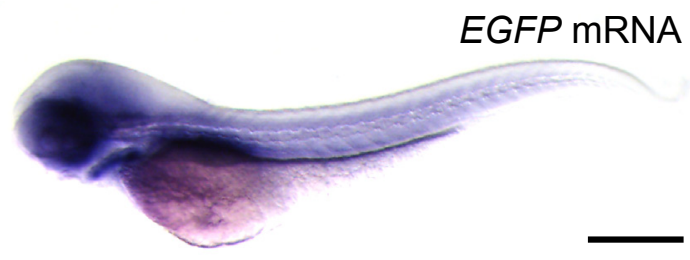

C

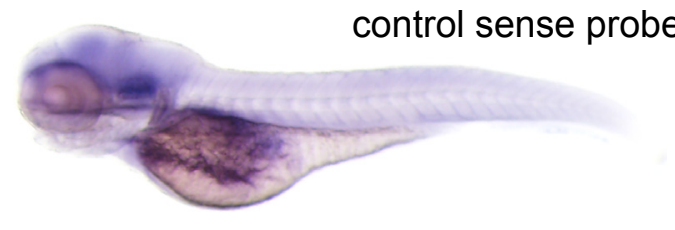

Fig. 2 (Above). sox9b transgenic line recapitulates the endogenous pattern of sox9b expression. (A-C) Lateral views of 72 hpf embryos. To detect sox9b, in situ hybridization was performed on whole embryos. (A) sox9b mRNA in transgenic embryos. (B) EGFP mRNA in transgenic embryos. (C) A sense probe was used as a control for nonspecific binding. Scale bars, 100 microns.

Fig. 3 (Right). Expression of sox9b:EGFP during embryonic and larval development. (A-E) Lateral views of sox9b:EGFP embryos and larvae. (A) Epifluorescent image at 24 hpf. (B-E) Confocal images at 48 hpf (B), $72 \mathrm{hpf}$ (C), $96 \mathrm{hpf}$ (D) and $120 \mathrm{hpf}$ (E). sox9b:EGFP expression is detected in the brain (purple arrows), eye, heart (white arrows), jaw, spinal cord (white arrowhead) and notocord (pink asterisks). Scale bars, 100 microns.
Zv9

phenotypes observed in humans, loss of sox9b in zebrafish results in craniofacial malformations, as well as heart, brain and retinal defects (Esain et al., 2010; Hofsteen et al., 2013; Yan et al., 2005).

We cloned a 2450 bp fragment near the sox9btranscriptional start site and fused it to an EGFP reporter to generate a transgenic sox9b:EGFP reporter line. Consistent with reported sox9b expression and function, we observed sox9b:EGFP in developing heart, skeletal and craniofacial structures, brain, retina, and ovaries. Consequently, we have generated a transgenic line that is useful for identifying and studying a number of zebrafish organs and tissues in which sox9b is expressed.

\section{Results and Discussion}

\section{Cloning and5' sequencing of the sox9b transcriptional start site}

This work was initiated using the Zv7 assembly of the zebrafish genome and targeted a region starting $\sim 2500$ base pairs upstream of the sox $9 b$ transcriptional start site. This region was amplified by
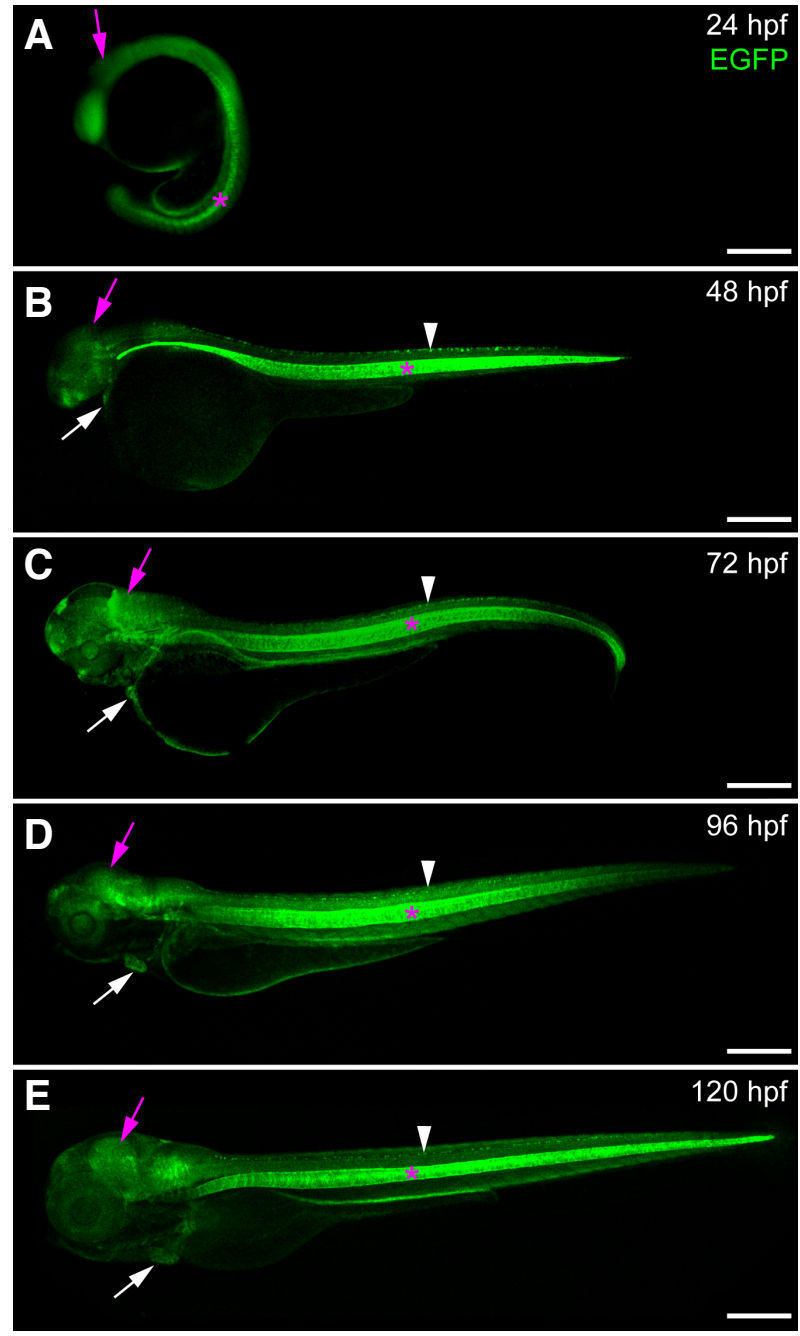
Fig. 4 (Left). Expression of sox9b:EGFP in the heart. (A-D) Confocal images of sox9b:EGFP expression in embryonic, larval, and adult zebrafish hearts. Cardiomyocytes are marked with activated leukocyte cell adhesion molecule (ALCAM; red in $A-C)$ and nuclei are stained with DAPI (blue); (A) Lateral view of a 24 hpf embryo. The developing heart is outlined and indicated by the arrow. (B,C) Ventral views of 72 and $96 \mathrm{hpf}$ hearts. Expression of sox9b:EGFP is detected in cardiomyocytes, the bulbus arteriosus (arrowheads in B and C), and in epicardial cells (arrows in C). (D) Ventral view of an adult heart. Expression of sox9b:EGFP in cardiomyocytes continues into adulthood. $V$ is ventricle; $A$ t, atrium; $B A$, bulbus arteriosus. Anterior is to the left in all panels. Scale bars, 50 microns.

Fig. 5 (Right). Expression of sox9b:EGFP in larval spine, skel-
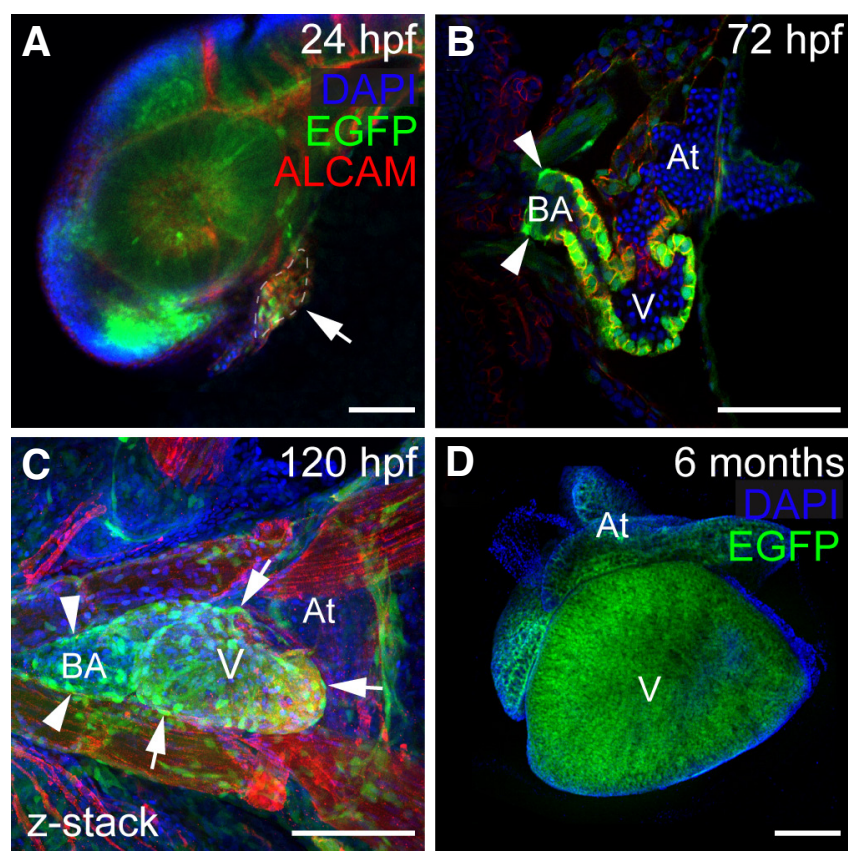

eton, and fin. (A-C) Lateral views of a 96 hpf and 120 larvae. Confocal images of sox9b:EGFP expression (green) in zebrafish spinal cord (A), notochord (A,B), and pectoral fin (C). (A) Neurons in the spinal cord are marked with activated leukocyte cell adhesion molecule (ALCAM; red in A). Expression of sox9b:EGFP is seen in a subset of neurons (arrows) and in the notochord. (B) sox9b:EGFP is also expressed in muscle associated with the spine (asterisks in B) and the developing pectoral fin. Collagen 2 (col2; red in B,C) is expressed in the fins. (A-C) Nuclei are stained with DAPI (blue). Scale bars, 50 microns.

PCR using zebrafish chromosomal DNA as template. According to the Zv7 assembly, our sequence should have a length of 2570 base pairs spanning scaffolds 302.4, 302.5 and 302.6; however, sequencing and alignment with CodonCode Aligner determined that our clone was 2450 base pairs long. The Zv7 build includes ambiguous nucleotides and additional bases, mostly GT repeats, not present in our sequence.

\section{TABLE 1}

\section{SOX9B:EGFP EXPRESSION AT DIFFERENT STAGES OF ZEBRAFISH DEVELOPMENT}

\begin{tabular}{lccccccc} 
sox9b:EGFP expression & $24 \mathbf{h p f}$ & $\mathbf{4 8} \mathbf{h p f}$ & $\mathbf{7 2} \mathbf{h p f}$ & $\mathbf{9 6} \mathbf{h p f}$ & $\mathbf{1 2 0} \mathbf{h p f}$ & $\mathbf{5} \mathbf{w k}$ & $\mathbf{6} \mathbf{m}$ \\
\hline Heart & $\mathrm{Y}$ & $\mathrm{Y}$ & $\mathrm{Y}$ & $\mathrm{Y}$ & $\mathrm{Y}$ & $\mathrm{Y}$ & $\mathrm{Y}$ \\
Forebrain & $\mathrm{Y}$ & $\mathrm{Y}$ & $\mathrm{Y}$ & $\mathrm{Y}$ & $\mathrm{Y}$ & $\mathrm{Y}$ & $\mathrm{Y}$ \\
Midbrain & $\mathrm{Y}$ & $\mathrm{Y}$ & $\mathrm{Y}$ & $\mathrm{Y}$ & $\mathrm{Y}$ & $\mathrm{Y}$ & $\mathrm{Y}$ \\
Hindbrain & $\mathrm{Y}$ & $\mathrm{Y}$ & $\mathrm{Y}$ & $\mathrm{Y}$ & $\mathrm{Y}$ & $\mathrm{Y}$ & $\mathrm{Y}$ \\
Olfactory Bulb & $-*$ & $\mathrm{Y}$ & $\mathrm{Y}$ & $\mathrm{Y}$ & $\mathrm{Y}$ & $\mathrm{NS} \mathrm{S}^{* *}$ & $\mathrm{Y}$ \\
Spinal Cord & $\mathrm{Y}$ & $\mathrm{Y}$ & $\mathrm{Y}$ & $\mathrm{Y}$ & $\mathrm{Y}$ & $\mathrm{Y}$ & $\mathrm{Y}$ \\
Notochord & $\mathrm{Y}$ & $\mathrm{Y}$ & $\mathrm{Y}$ & $\mathrm{Y}$ & $\mathrm{Y}$ & $\mathrm{NS}$ & $\mathrm{NS}$ \\
Eye & $\mathrm{Y}$ & $\mathrm{Y}$ & $\mathrm{Y}$ & $\mathrm{Y}$ & $\mathrm{Y}$ & $\mathrm{NS}$ & $\mathrm{Y}$ \\
Jaw/Jaw cartilages & - & $\mathrm{Y}$ & $\mathrm{Y}$ & $\mathrm{Y}$ & $\mathrm{Y}$ & $\mathrm{Y}$ & $\mathrm{Y}$ \\
Branchial Arches & $\mathrm{NS}$ & $\mathrm{Y}$ & $\mathrm{Y}$ & $\mathrm{Y}$ & $\mathrm{Y}$ & $\mathrm{Y}$ & $\mathrm{Y}$ \\
Pectoral Fin & - & $\mathrm{Y}$ & $\mathrm{Y}$ & $\mathrm{Y}$ & $\mathrm{Y}$ & $\mathrm{Y}$ & $\mathrm{Y}$ \\
Vertebrae & - & - & - & - & - & $\mathrm{Y}$ & $\mathrm{Y}$ \\
Ovary & - & - & - & - & - & $\mathrm{Y}$ & $\mathrm{Y}$ \\
Intestine & $\mathrm{NS}$ & $\mathrm{NS}$ & $\mathrm{NS}$ & $\mathrm{NS}$ & $\mathrm{NS}$ & $\mathrm{Y}$ & $\mathrm{Y}$ \\
Skeletal Muscle & $\mathrm{NS}$ & $\mathrm{NS}$ & $\mathrm{Y}$ & $\mathrm{Y}$ & $\mathrm{Y}$ & $\mathrm{Y}$ & $\mathrm{Y}$ \\
Jaw Muscle & $\mathrm{NS}$ & $\mathrm{NS}$ & $\mathrm{Y}$ & $\mathrm{Y}$ & $\mathrm{Y}$ & $\mathrm{NS}$ & $\mathrm{NS}$ \\
Cranial Nerves & $\mathrm{NS}$ & $\mathrm{NS}$ & $\mathrm{Y}$ & $\mathrm{Y}$ & $\mathrm{Y}$ & $\mathrm{NS}$ & $\mathrm{NS}$ \\
\hline
\end{tabular}

Note: 5-10 embryos were scored for expression at each time point for each organ or structure. ${ }^{*}(-)=$ organ/structure had not yet formed. ${ }^{* *}(\mathrm{NS})=$ Not scored at this time point.
The sequence that we found upstream of sox9b varies substantially from build Zv9. Two portions of our cloned sequence, from -1 to -156 and -246 to -1361 , produced a strong match with Zv9 (Fig. 1) and previous sequence builds. The remainder of our clone,
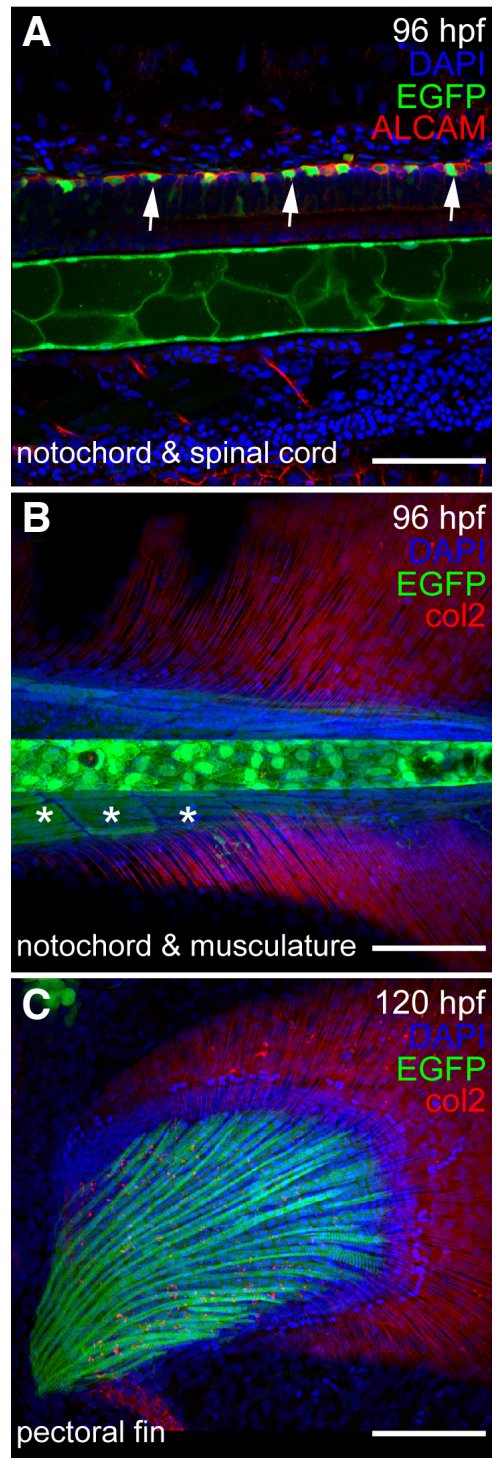
from -1362 to -2450 , matches well in scaffolds 302.5 and 302.6 in build Zv7, but this sequence has been lost in subsequent builds. In build Zv9 a short section of our clone, from -157 to -245, was replaced with a $1378 \mathrm{bp}$ segment not found in our sequence. Given that we are able to produce amplicons anchored within our predicted sequence and within the well-established first exon of sox9b using genomic DNA from the AB strain, we conclude that our sequence for this region (Supplementary Fig. S1) and build Zv7 are more accurate for this locus.

\section{Creation and confirmation of a sox9b:EGFP reporter}

We used the $2450 \mathrm{bp}$ sox $9 \mathrm{~b}$ promoter fragment to create an EGFP reporter plasmid and transgenic zebrafish reporter line. To verify that the sox9b:EGFP transgenic line recapitulated the endogenous pattern of sox9b expression, we performed in situ hybridization and compared expression patterns of EGFP mRNA with sox9b mRNA (Fig. 2 and data not shown). We found that EGFP and sox9b mRNA expression patterns were consistent in embryos and larvae during the first five days of development, which indicates that the $2450 \mathrm{bp}$ promoter fragment is sufficient 
to drive expression of EGFP mRNA in a pattern that resembles endogenous expression of sox $9 \mathrm{~b}$ mRNA. Fig. 2 shows the consistent expression patterns in $72 \mathrm{hpf}$ larvae.

\section{Expression of sox9b:EGFP during early embryonic and larval development}

We followed sox9b:EGFP expression in developing zebrafish from 24 to $120 \mathrm{hpf}$ (Fig. 3). Expression was detected in tissues previously shown to express sox9b, including developing heart (Hofsteen et al., 2013), jaw (van der Velden et al., 2013), brain (Esain et al., 2010), retina (Yokoi et al., 2009), and ovary (Chiang et al., 2001) (see also Table 1). For a more complete characterization of the sox9b:EGFP transgenic line, we examined reporter expression in greater detail during cardiac, skeletal, craniofacial, neural, retinal, and ovarian development.
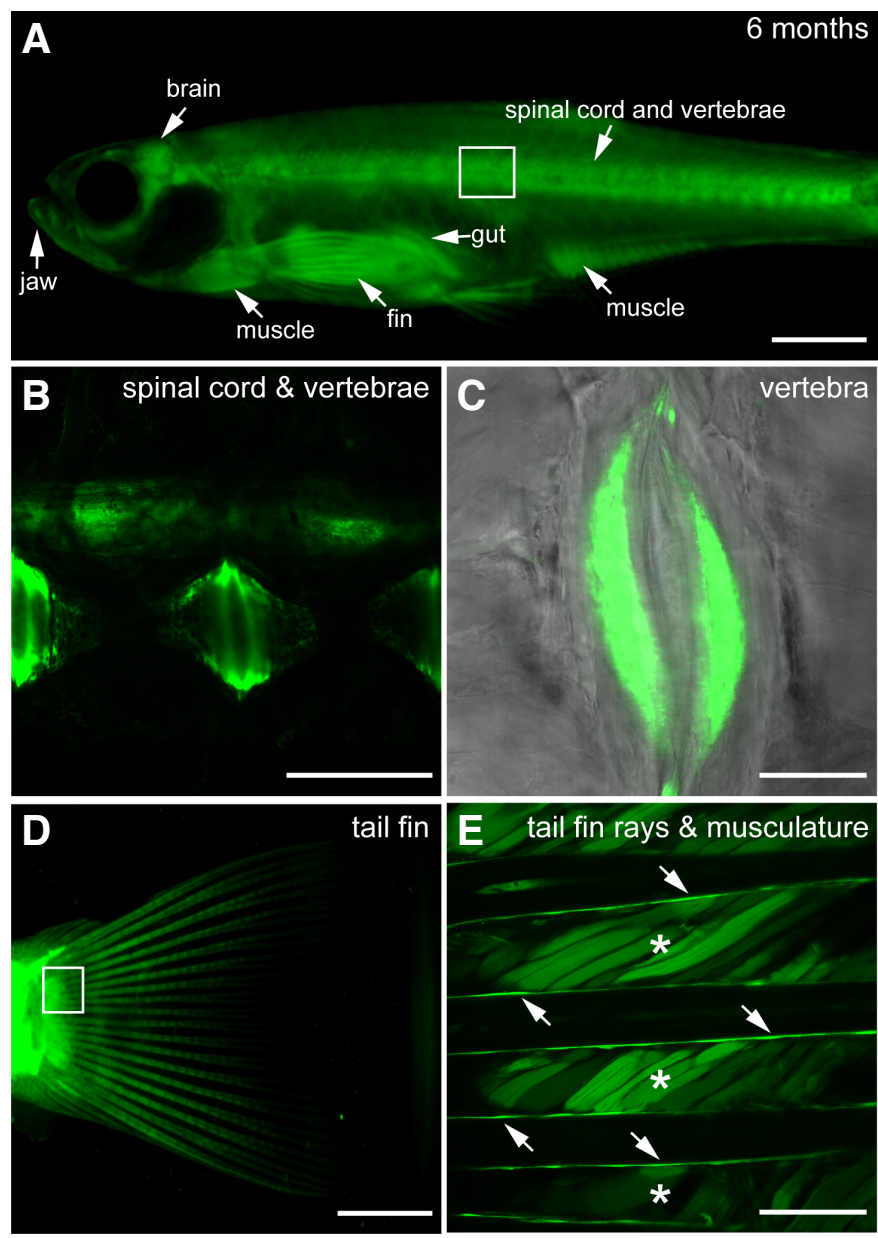

\section{Cardiac development}

In zebrafish, sox9b is necessary for proper development of the proepicardial progenitors cells, the epicardium, and heart valves (Hofsteen et al., 2013). Expression of sox9b:EGFP was first observed in the developing zebrafish heart at $24 \mathrm{hpf}$ (Fig. $4 \mathrm{~A})$ and sox9b:EGFP expression continued to be detected into adulthood (Fig. 4D). We used ALCAM immunostaining to visualize the myocardium and found sox9b:EGFP expression in ventricular and atrial cardiomyocytes in both embryonic and adult hearts (Fig. 4B-D). In addition, we observed expression in epicardial cells (arrows in Fig. 4C) and the bulbous arteriosus (Fig. 4B and C).

\section{Skeletal and craniofacial development}

Humans with $C D$ have numerous skeletal malformations. Consistent with these phenotypes, expression of sox9b in zebrafish was detected in the skeleton, fins and jaw during embryonic, larval stages and adult stages. Throughout embryonic and larval development, sox9b:EGFP expression was found in the notochord (Fig. 5A and B) and spinal cord (Fig. 5A) as well as the pectoral (Fig. 5C) and tail fins (data not shown). In the adult, sox9b:EGFP expression was found in the spinal column (Fig. 6A and $B$ ), vertebrae (Fig. 6A-C), and the pectoral and tail fins (Fig. $6 \mathrm{D}$ and $6 \mathrm{E})$. In both larvae and adults, sox9b:EGFP expression was detected in muscles associated with the spine and fins (Fig. 5A, Fig. 6A and 6E).

In the developing jaw, sox9b:EGFP was expressed in the perichondrium, a layer of connective tissue surrounding the
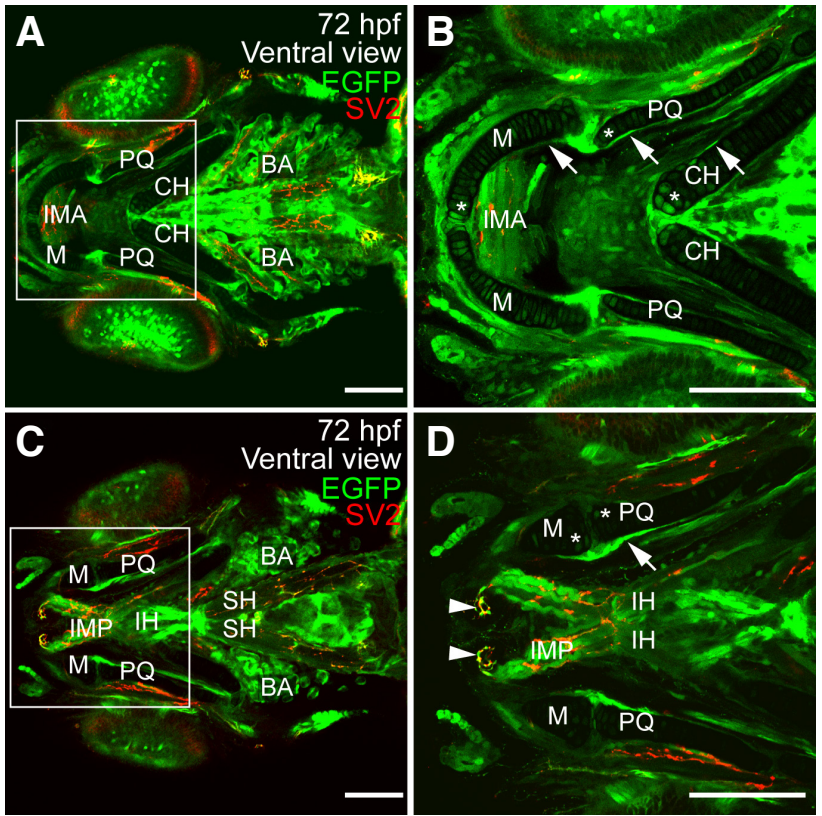

Fig. 6 (Left). Expression of sox9b:EGFP in adult skeleton and skeletal muscle. (A-E) Lateral views of six month old sox9b:EGFP transgenic fish. (B) Area boxed in (A). Expression is detected in the spinal cord and vertebrae. (C) Magnification of the sox9b:EGFP expressing growth plates in the vertebrae. (D) Muscle associated with the tail fin and rays within the tail fin express sox9b:EGFP. (E) Magnification of the box in (D). Asterisks mark the muscle while arrows point to the rays. Scale bars in $(A, D), 150$ microns. Scale bars in $(B, C, E), 50$ microns.

Fig. 7 (Right). Expression of sox9b:EGFP in larval jaw and associated skeletal muscle. (A-D) Ventral views of 72 hpf larvae stained for synaptic vesicles (SV2; red). sox9b:EGFP expression was detected in the perichondrium and in chondrocytes. (B,D) Magnification of regions in the white boxes in panels $(A, C)$ respectively. Expression is associated with the ceratohyal (CH), Meckel's (M), palatoquadrate (PQ), ceratobranchials (not shown) and basihyal (not shown) cartilages. Expression was also detected in muscles associated with the jaw including the intermandibularis anterior (IMA), intermandibularis posterior (IMP), interhyoideus (IH), and sternohyoideus (SH). sox9b:EGFP was also observed in the branchial arches (BA). Scale bars, 50 microns. 

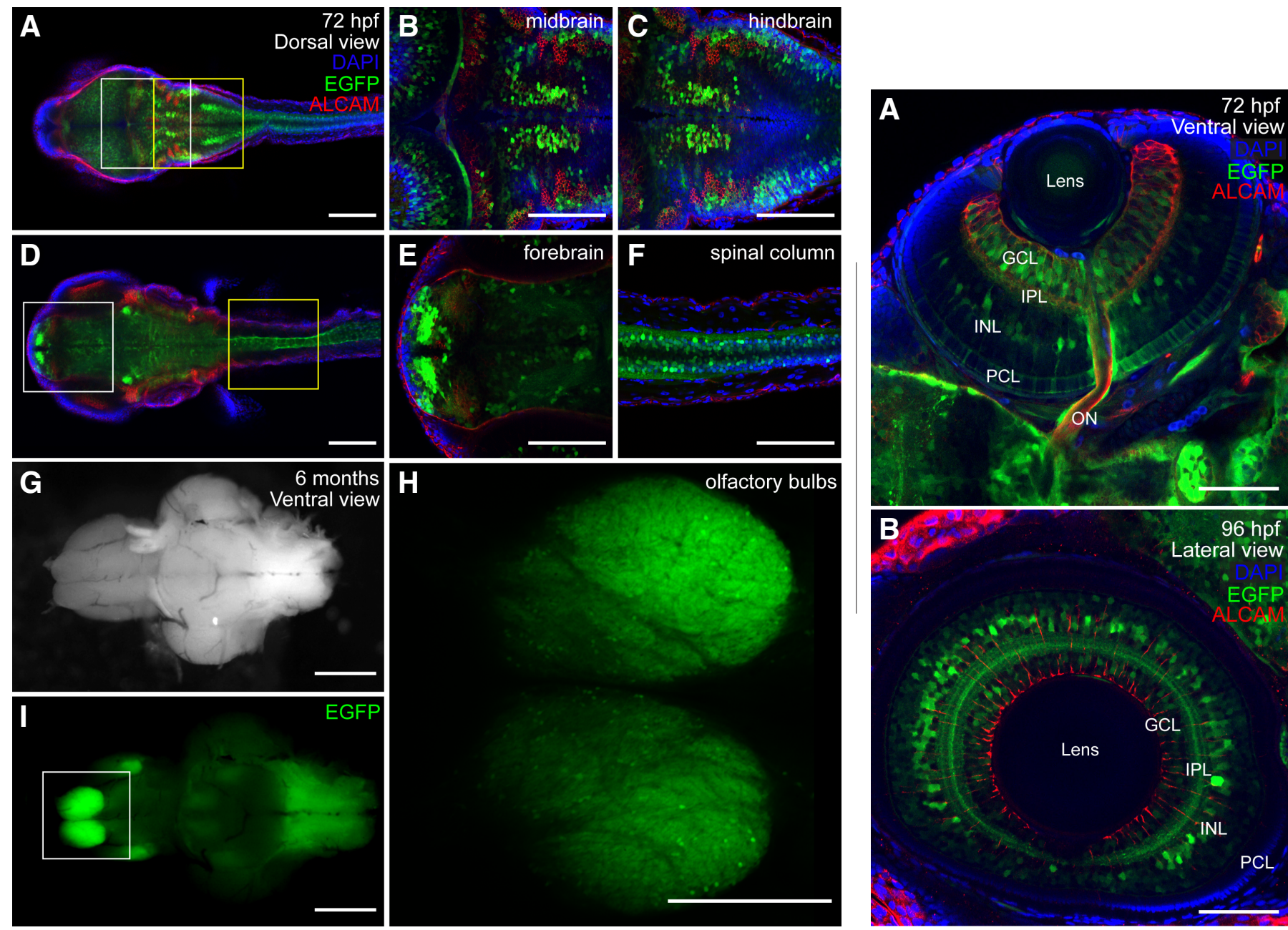

Fig. 8 (Left). Expression of sox9b:EGFP in larval and adult brain. (A-F) Confocal images showing dorsal views of a 72 hpf larval zebrafish. Larvae were stained for ALCAM (red) and mounted in Vectashield with DAPI (blue). (B,C) Magnification of the regions in the white and yellow boxes in (A). (E,F) Magnification of the regions in the white and yellow boxes in (D). Expression of sox9b:EGFP in the fore-, mid-and hindbrain as well as in the spinal cord. (G,I) Bright field images and epifluorescence and ventral views of an adult brain. (H) Magnification of olfactory bulb boxed in (I). Scale bars, 50 microns.

Fig. 9 (Right). Expression of sox9b:EGFP in retina. (A,B) Ventral and lateral views of larval eyes at 72 and 96 hpf stained for ALCAM (red) and mounted in Vectashield with DAPI (blue). (A) At 72 hpf, sox9b:EGFP expression was observed in a subset of cells in the photoreceptor cell layer (PCL), inner nuclear layer (INL), and ganglion cell layer (GCL) and within the inner plexiform layer (IPL). (B) By 96 hpf, sox9b:EGFP expression in the PCL was waning, however sox9b:EGFP was visible in the INL, IPL, and GCL. Scale bars, 50 microns.

craniofacial cartilages, and in chondrocytes (Fig. 7A-D). During embryonic and larval stages, expression was associated with the ceratohyal, Meckel's, palatoquadrate, ceratobranchials (not shown) and basihyal (not shown) cartilages (Fig. 7A-D). Expression was also detected in muscles associated with the jaw including the intermandibularis anterior (Fig. 7A and B), intermandibularis posterior (Fig. 7C and D), interhyoideus (Fig. 7C and D), and sternohyoideus (Fig. 7C). In addition, sox9b:EGFP was observed in the branchial arches at 72, 96, and 120 hpf (Fig. 7A and C).

\section{Nervous system}

Sox9 plays critical roles during vertebrate neural development. In zebrafish hindbrain, fibroblast growth factor receptor signaling regulates gliogenesis by inducing sox9a and sox9b expression (Esain et al., 2010). We observed sox9b:EGFP expression in the developing nervous system beginning at $24 \mathrm{hpf}$ and continuing into adulthood (Fig. 2 and Fig. 8). sox9b:EGFP expression was detected in the fore-, mid- and hindbrain (Fig. 2 and Fig. 8A-E and $\mathrm{G}$ ). We also observed expression in the spinal cord (Fig. 8F and Fig. 5A), cranial nerves and lateral line neuromasts (data not shown). sox9b:EGFP was observed in what appear to be axon projections (asterisks in Fig. 8E) indicating that sox9b may be expressed in neurons in the forebrain.

Signs of CD include underdeveloped or absent olfactory tracts and bulbs (Houston et al., 1983). Consistent with these findings, we found sox9b:EGFP expression in the developing olfactory organs (data not shown) and corresponding neural tissue during embryogenesis (Fig. 8D and E), and, in adult fish, strong expression was seen in olfactory epithelium (data not shown) and olfactory bulbs (Fig. $8 \mathrm{H}$ and I). 

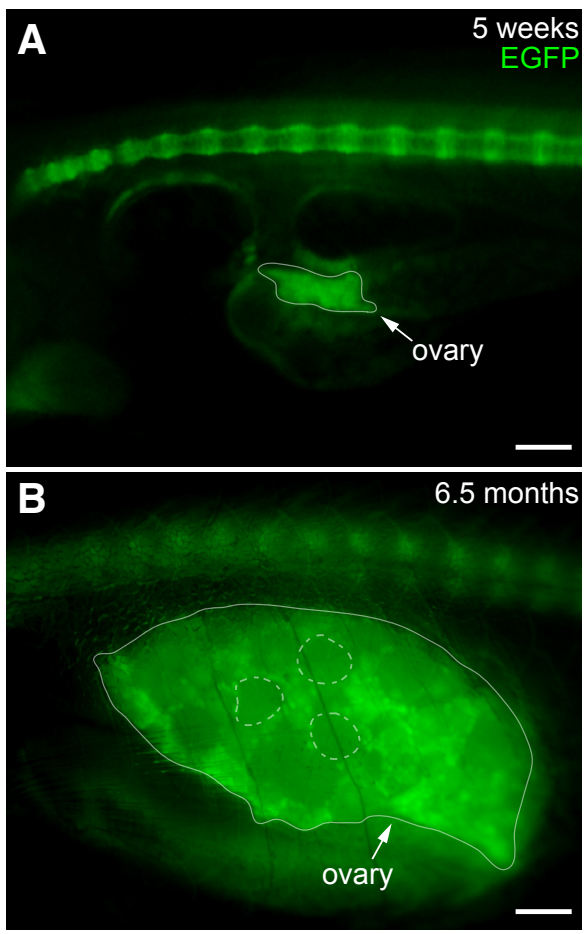

Fig. 10. Expression of sox9b:EGFP in ovary. Lateral views of juvenile (A) and adult (B) ovary. The ovaries are outlined with a solid line. Examples of mature follicles are outlined with dashed circles. Scale bars, 100 microns.

\section{Retina}

Both sox9b and sox9a are required for retinal differentiation and regulate the expression of key genes during zebrafish retinogenesis (Yokoi et al., 2009). Consistent with Chiang et al., (2001), we observed sox9b:EGFP expression in the retina at $24 \mathrm{hpf}$ when retinal ganglion cells are being generated. At $72 \mathrm{hpf}$, sox9b:EGFP expression was observed in a subset of cells in the photoreceptor cell layer, inner nuclear layer, and ganglion cell layer, as well as projections within the inner plexiform layer (Fig. 9A). By $96 \mathrm{hpf}$, sox9b:EGFP expression in the photoreceptor cell layer was waning, however sox9b:EGFP was clearly visible in the inner nuclear layer, inner plexiform layer and ganglion cell layer (Fig. 9B).

\section{Ovary}

In humans, the SRY gene has been identified as the major sex determination gene on the $Y$ chromosome. A peak of Sry transcription factor activity induces Sox9 expression, leading to the development of primary and secondary male sex characteristics. In zebrafish, the developing ovary expresses sox9b, whereas the developing testis expresses sox9a (Chiang et al., 2001). Consistent with in situ hybridization results (Chiang et al., 2001), we found sox9b:EGFP expression in ooplasm of oocytes within the immature ovaries of juvenile zebrafish (Fig. 10A). sox9b:EGFP was also found in the mature adult ovary. In adults, the sox9b:EGFP signal appeared stronger in the ooplasm of the smaller, less mature perinucleolar oocytes compared to larger, more mature vitellogenic stage follicles (Fig. 10B).

\section{Conclusions}

Sox9 and the corresponding co-orthologs of Sox9, sox9a and sox $9 b$, are important in a number of developmental processes that are essential for human health. Herein we described construction of a sox $9 \mathrm{~b}$ reporter line and provided broad observations about where the reporter is expressed during development. Given that we find sox $9 b$ expression to be associated with the development of many organs at many different developmental stages, our transgenic reporter line will be useful tool for investigators studying diverse processes in developmental biology as well as genetics and toxicology.

\section{Materials and Methods}

\section{Zebrafish strains and husbandry}

Zebrafish were maintained as described in (Hofsteen et al., 2013). The $T g\left(-2421 /+29 s o x 9 b: E_{\text {GFP }}\right.$ ) line was generated in casper (roya9; mitfaw2) and $A B$ backgrounds (White et al., 2008). The casper line, used for all imaging experiments, is referred to as sox $9 b$ :EGFP. All procedures involving animals were approved by the Animal Care and Use Committee at the University of Wisconsin-Madison, and adhered to the NIH "Guide for the Care and Use of Laboratory Animals."

\section{Cloning sox9b genomic fragments}

Genomic DNA was extracted from zebrafish embryos for use as a PCR template (Xiong et al., 2008). We used the zebrafish genome build Zv7 to design PCR primers. Using the build information, we amplified a 2,450 bp fragment extending in the 5 'direction from the base pair immediately adjacent to the transcriptional start site. The 2450 bp PCR product was inserted into the $\mathrm{PCR}$-II TOPO vector for propagation (Invitrogen, Carlsbad, $\mathrm{CA})$. The 2450 sox $9 \mathrm{~b}$ clone was inserted upstream of EGFP in the Tol2 transgenesis system as previously described to make reporter constructs (Kwan et al., 2007). Primers used are listed in Supplemental Table S1. All clones were sequenced at the UW Biotechnology Center.

\section{sox9b:EGFP transgenic embryos}

The 2450 bp sox $9 b$ reporter construct $(20 \mathrm{ng} / \mathrm{\mu l})$ was injected into 1-2 cell stage $A B$ or casper embryos and injected embryos were raised to adulthood. Adult founder fish were identified by crossing potential founders to either $A B$ or casper fish and screening offspring for sox $9 b$ :EGFP expression. sox9b:EGFP positive embryos were raised to generate a F1. sox9b:EGFP-positive F1 adults were incrossed to generate a homozygous F2 line with a strong sox9b:EGFP signal. Images shown are from representative $\mathrm{F} 1$ and $\mathrm{F} 2$ embryos, juveniles, and adults.

\section{Whole-mount in situ hybridization}

Whole mount in situ hybridization was performed as previously described (Hofsteen et al., 2013). Anti-sense sox9b and EGFP RNA probes were synthesized from PCR amplicons made from plasmid DNA ( $p C M V$ Sport6sox9b, Open Biosystems, Huntsville, AL) and p3E-EGFPpA, (Kwan et al., 2007) as the template. Primers used for sox9b were: $F$ ', 5'-agc cac acc cct ctt aca gcc a-3'; sox9b R', 5'-cga tgt taa tac gac tca cta tag gga gtc agc gtg agg atg cgc $\mathrm{t}-3$ '. The resulting sox9b probe (537 bp) spans a region encompassing base pairs 2048 to 2584 in the 3' UTR of the sox9b-001 cDNA. EGFP F', 5'-gac ggc gac gta aac ggc ca-3'; and EGFP $R^{\prime}, 5^{\prime}$-cga tgt taa tac gac tca cta tag ggt tgc tca ggg cgg act ggg t-3'. As a control, a sense EGFP probe was synthesized using the following primers: EGFP F', 5'-cga tgt taa tac gac tca cta tag ggg acg gcg acg taa acg gcc a-3' and EGFP R', 5'-ttg ctc agg gcg gac tgg gt-3'. The resulting EGFP probe (572 bp) spans a region encompassing base pairs 58 to 629 of the 
EGFP gene. A T7 promoter (bold) was added to the reverse sox $9 \mathrm{~b}$ primer, reverse EGFP primer and forward control primer for in vitro transcription of the RNA probe with T7 RNA polymerase. In situ hybridization samples were imaged with an Olympus DP72 digital camera attached to an Olympus SZX16 stereomicroscope.

\section{Fluorescent immunohistochemistry and confocal microscopy}

Antibody staining was performed as previously described (Hofsteen et al., 2013). Primary antibodies were used at the following dilutions in phosphate buffered saline with $4 \%$ bovine albumin serum and $0.3 \%$ Triton (PBT): activated leukocyte cell adhesion molecule (ALCAM; ZIRC) 1:50, synaptic vesicles (SV2; DSHB) 1:100, and collagen type II (II-II6B3; DSHB) 1:50. Secondary anti-mouse antibodies (Alexa 568; Invitrogen) were used at 1:200 dilution in PBT. Embryos were mounted in Vectashield or Vectashield with DAPI (Vector Laboratories). Confocal images were collected on an Olympus Fluoview FV1000 microscope and were processed using Adobe Photoshop.

\section{Acknowledgements}

We thank Dorothy Nesbit, Dr. Kevin Lanham, Glen Threadgold from the Wellcome Trust Sanger Institute, and Jeremy Niece of the University of Wisconsin Biotech Center. The collagen type II monoclonal antibody developed by R. Holmdahl and K. Rubin was obtained from the Developmental Studies Hybridoma Bank, created by the NICHD of the NIH and maintained at The University of lowa, Department of Biology, lowa City, IA 52242. This research was supported by NIH grant R01 ES012716 (WH \& REP), K99 ES0238 (JSP), K01 OD010462 (TRB) and FRB was supported by a supplement to NIH grant R01 ES012716 for underrepresented minorities and by an Advanced Opportunity Fellowship from the University of Wisconsin, Science and Medical School, Graduate Research Scholars Program.

\section{Author contributions}

JSP performed the fluorescent immunohistochemistry and confocal microscopy, JSP \& TRB collected the epifluorescent images, KMX, FRB \& AJG cloned the 2450 fragment, \& performed sequencing \& genotyping. TRB generated the 2450 Casper line. KMX \& PH performed in situs. JSP, TRB, FRB, WH and REP wrote the manuscript.

\section{References}

CHIANG E F L, PAI C I, WYATT M, YAN Y L, POSTLETHWAIT J, and CHUNG B C (2001). Two sox9 genes on duplicated zebrafish chromosomes: Expression of similar transcription activators in distinct sites. Dev Bio 231: 149-163.

ESAIN V, POSTLETHWAIT J H, CHARNAY P, and GHISLAIN J (2010). FGF-receptor signalling controls neural cell diversity in the zebrafish hindbrain by regulating olig2 and sox9. Development 137: 33-42.

FOSTER J W, DOMINGUEZ-STEGLICH M A, GUIOLI S, KWOK C, WELLER P A STEVANOVIC M, WEISSENBACHJ, MANSOURS, YOUNGID, GOODFELLOW
PN, BROOKJD, and SCHAFERAJ (1994). Campomelic dysplasia and autosomal sex reversal caused by mutations in an SRY-related gene. Nature 372: 525-530.

HOFSTEEN P, PLAVICKI J, JOHNSON S D, PETERSON R E, and HEIDEMAN W (2013). Sox9b is required for epicardium formation and plays a role in TCDDinduced heart malformation in zebrafish. Mol Pharmacol 84: 353-360.

HOUSTON C S, OPITZ J M, SPRANGER J W, MACPHERSON R I, REED M H, GILBERT E F, HERRMANN J, and SCHINZEL A (1983). The campomelic syndrome: review, report of 17 cases, and follow-up on the currently 17-year-old boy first reported by Maroteaux et al., in 1971. Am J Med Genet 15: 3-28.

KING-HEIDENTC, MEHTAV, XIONG KM, LANHAM KA, ANTKIEWICZDS, GANSER A, HEIDEMAN W, and PETERSON RE (2012). Reproductive and developmental toxicity of dioxin in fish. Mol Cell Endocrinol 354: 121-138.

KWAN K M, FUJIMOTO E, GRABHER C, MANGUM B D, HARDY M E, CAMPBELL D S, PARANT J M, YOST H J, KANKI J P, and CHIEN C B (2007). The Tol2kit: A multisite gateway-based construction kit for Tol2 transposon transgenesis constructs. Dev Dyn 236: 3088-3099.

MORAIS DA SILVA S, HACKER A, HARLEY V, GOODFELLOW P, SWAIN A, and LOVELL-BADGE R (1996). Sox9 expression during gonadal development implies a conserved role for the gene in testis differentiation in mammals and birds. $\mathrm{Nat}$ Genet 14: 62-68.

SCOTT C E, WYNN S L, SESAY A, CRUZ C, CHEUNG M, GOMEZ GAVIRO M V, BOOTH S, GAO B, CHEAH K S, LOVELL-BADGE R, and BRISCOE J (2010). SOX9 induces and maintains neural stem cells. Nature Neurosci 13: 1181-1189.

SMITH C L, BAEK S T, SUNG C Y, and TALLQUIST M D (2011). Epicardial-derived cell epithelial-to-mesenchymal transition and fate specification require PDGF receptor signaling. Circ Res 108: e15-26.

STOLT C C, LOMMES P, SOCKE, CHABOISSIER M C, SCHEDLA, and WEGNERM (2003). The Sox9 transcription factor determines glial fate choice in the developing spinal cord. Genes Dev 17: 1677-1689.

VAN DER VELDEN Y U, WANG L, QUEROL CANO L, and HARAMIS A P (2013) The polycomb group protein ring $1 \mathrm{~b} / \mathrm{rnf} 2$ is specifically required for craniofacial development. PLoS One 8: e73997.

WAGNER T, WIRTH J, MEYER J, ZABEL B, HELD M, ZIMMER J, PASANTES J, BRICARELLI F D, KEUTELJ, HUSTERT E, WOLFU, TOMMERUP N, SCHEMPP W, and SCHERER G (1994). Autosomal sex reversal and campomelic dysplasia are caused by mutations in and around the SRY-related gene SOX9. Cell 79: 1111-1120.

WHITE R M, SESSAA, BURKE C, BOWMANT, LEBLANC J, CEOL C, BOURQUE C DOVEY M, GOESSLING W, BURNS C E, and ZON L I (2008). Transparent adult zebrafish as a tool for in vivo transplantation analysis. Cell Stem Cell 2: 183-189.

XIONG KM, PETERSONRE, and HEIDEMANW (2008). Aryl Hydrocarbon ReceptorMediated Down-Regulation of Sox9b Causes Jaw Malformation in Zebrafish Embryos. Mol Pharmacol 74: 1544-1553.

YAN Y L, WILLOUGHBY J, LIU D, CRUMP J G, WILSON C, MILLER C T, SINGERA KIMMEL C, WESTERFIELD M, and POSTLETHWAIT J H (2005). A pair of Sox: distinct and overlapping functions of zebrafish sox 9 co-orthologs in craniofacial and pectoral fin development. Development 132: 1069-1083.

YOKOI H, YAN Y L, MILLER M R, BREMILLER R A, CATCHEN J M, JOHNSON E A, and POSTLETHWAIT J H (2009). Expression profiling of zebrafish sox9 mutants reveals that Sox9 is required for retinal differentiation. Dev Biol 329: 1-15. 


\section{Further Related Reading, published previously in the Int. J. Dev. Biol.}

Expression of the mediators of dioxin toxicity, aryl hydrocarbon receptor (AHR) and the AHR nuclear translocator (ARNT), is developmentally regulated in mouse teeth

Carin Sahlberg, Raimo Pohjanvirta, Yuguang Gao, Satu Alaluusua, Jouko Tuomisto and Pirjo-Liisa Lukinmaa

Int. J. Dev. Biol. (2002) 46: 295-300

http://dx.doi.org/10.1387/ijdb.12068950

Large scale genetics in a small vertebrate, the zebrafish

$P$ Haffter and C Nüsslein-Volhard

Int. J. Dev. Biol. (1996) 40: 221-227

http://dx.doi.org/10.1387/ijdb.8735932

Cloning and developmental expression of zebrafish pdzrn3

Luciana Dente, Gaia Gestri, Michael Tsang, Tetsuhiro Kudoh, Stephen W. Wilson, Igor B.

Dawid and Massimiliano Andreazzoli

Int. J. Dev. Biol. (2011) 55: 989-993

http://dx.doi.org/10.1387/ijdb.113437ld

Zebrafish enhancer trap line recapitulates embryonic aquaporin 1a expression pattern in vascular endothelial cells

Kira Rehn, Kuan Shen Wong, Darius Balciunas and Saulius Sumanas

Int. J. Dev. Biol. (2011) 55: 613-618

http://dx.doi.org/10.1387/ijdb.103249kp

Loss of plakophilin 2 disrupts heart development in zebrafish

MiriamA. Moriarty, Rebecca Ryan, Pierce Lalor, Peter Dockery, Lucy Byrnes and Maura Grealy Int. J. Dev. Biol. (2012) 56: 711-718

http://dx.doi.org/10.1387/ijdb.113390mm

5 yr ISI Impact Factor $(2013)=2.879$

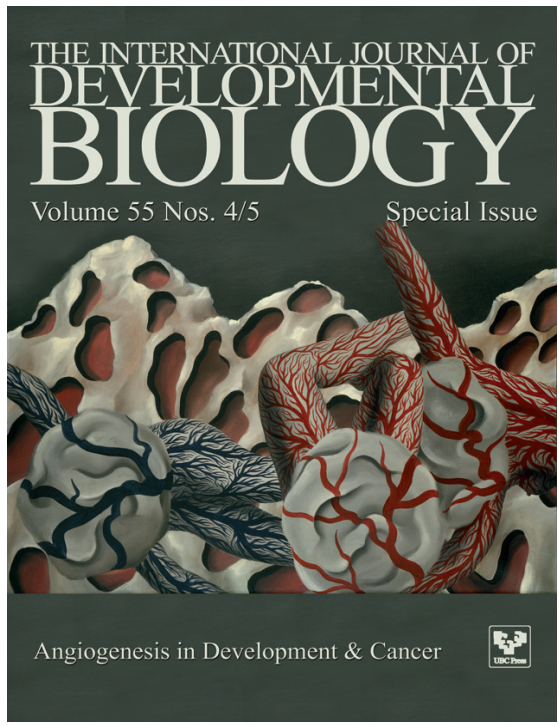

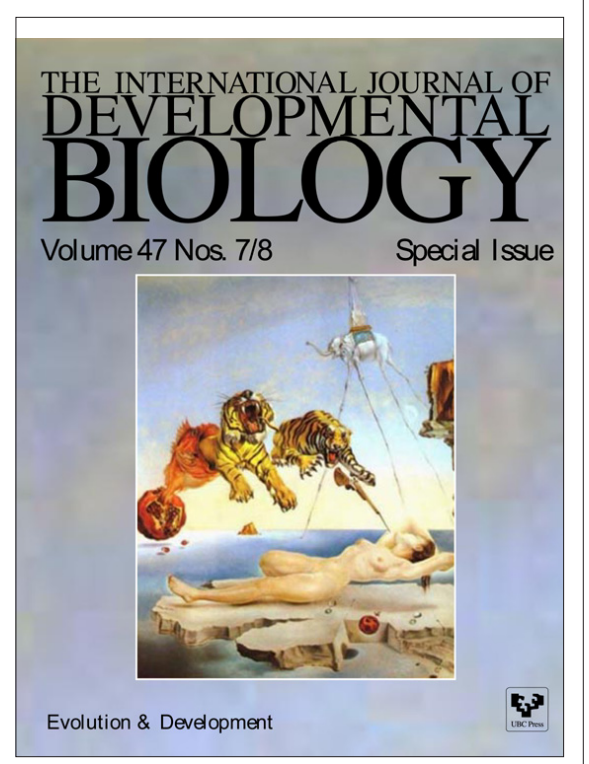

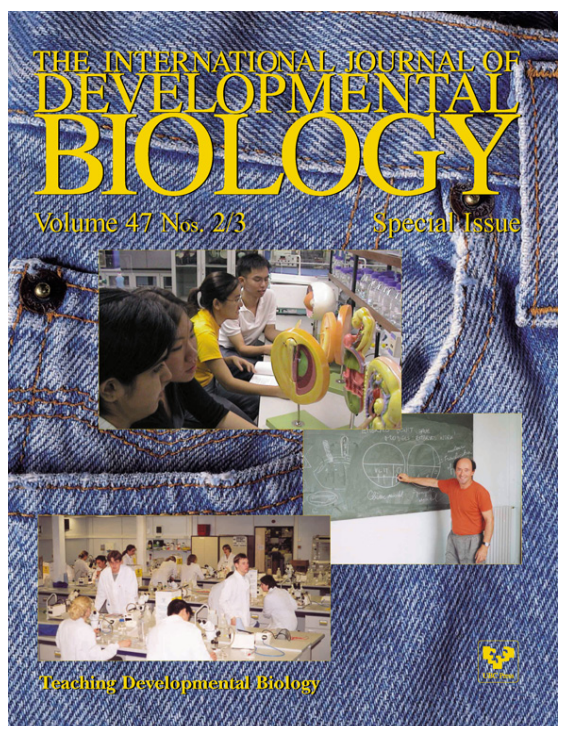

